\title{
O evolver eco-necessário da arte-educação dos adolescentes e a ameaça de um tempo redutor
}

\author{
Elisabete Oliveira \\ Associação de Professores de Expressão e Comunicação Visual (APECV)
}

\begin{abstract}
Resumo
Esta investigação parte do conceito-tempo, construto para regular o viver, sendo constante a mudança, contínua, necessária, fluir que impõe actualização sustentada, exigindo auto-ecocompatibilização do actor - respondendo à envolvente e com os outros. No actual contexto da comunicação à distância e explosão da tele/web-tecnologia instrumental, será co-construível a utopia, de uma EEV para todos, com esses meios, orientando a energia transformadora do possível para o imaginável. Compreendemos 3 enfoques: (1) Motor/factores da educação estética visual (EEV) para os adolescentes em Portugal em sincronia no presente: Projectos referenciais de 11 tendências, em paralelo diacrónico com projectos pioneiros, marcos no desenvolvimento curricular em EEV. (2). Tempo legislado, de flexibilização e autonomia curricular, com as autarquias, e meios para o ensino-aprendizagem específico; necessário à docência, investigação-acção e arte do professor. (3) Tempo histórico disciplinar da EEV e o potencial de um Exploratório contínuo dos projectos escolares pioneiros: Património cultural imaterial - de memória e referencial de acção, para o não retrocesso, em eco-compatibilização contínua, nacional e internacionalmente. Numa metodologia de investigação-acção, por questionamento e estudo de caso, buscámos referenciais (não modelos) com utilidade didáctica, sem pretender generalização. Em conclusão, urgirão: (1) Vigilância dos constrangimentos redutores emergentes de distanciamento; dificuldades de acesso tecnológico, tempo e espaço; e a ameaça ao projecto de trabalho partilhado. (2) Garantia em todo o País, de actualização da formação de professores em EEV. (3) Maximização de sinergias, pela partilha de referenciais e práticas estruturantes, em plataformas e redes, como pelo ExplorEAUL. Meta: qualificação da EEV de todos, em auto-eco-compatibilização contínua.
\end{abstract}

Palavras-Chave: Currículo e Didáctica da Educação Estética Viisual / Exploratório de projectos referenciais / Formação de Professores / Património Visuo-Cultural da EEV / Projecto de trabalho.

\begin{abstract}
This research departs from a concept of time, a construct for living regulation, with change as a continuous and necessary constant, a flow that imposes sustained updating, requiring the actor's self-eco-compatibilization- answering the environment and with others. Within the actual context of distance communication and instrumental tele/web/technology explosion, it will be possible coconstruct utopia, one of VAE for all, with these means, orienting the transforming energy from the possible to the imaginable. We will comprehend 3 focuses: (1) Motor/factors of visual aesthetic educatiom (VAE) for Adolescents in Portugal, synchronously at present days: reference Projects of 11 tendencies, in a diachronic parallel with pioneer project, VAE curriculum development milestones. (2) Legislation time, of curriculum flexibility and autonomy, with municipalities, and means for specific teaching-learning; necessary for teacher's teaching, action-research and art. (3) VAE discipline historic time and the potential of a continuous Exploratory of school pioneer projects; an imtangible heritage - of memory and an action reference for no serback, in national and international continuous eco-compatibilization. Within an action-research methodology, by questionnaire and study case, we searched for references (not models) with didactic usefulness, without pretending generalization. In conclusio,: they will be necessary: (1) Vigilance of reducing constraints emerging from distance; difficulties of technological access, time and space; and menace to the shared project of work. (2) Guarantee all over the Country, of VAE teacher training updating. (3) Synergies maximization, through sharing of references and structuring practices, in nets and platforms, such as by the ExplorEAUL. Goal: VAE for all qualification, through continuous self-eco-compatibilization.
\end{abstract}

Keywords: Visual-Cultural Patrimony of Visual Aesthetic Education / Exploratory of referential projects / /Project of Work./ Teacher Education / Visual Aesthetic Education Curriculum and Didactics. 


\section{Introdução}

A nossa investigação enraíza-se em conceitos de tempo como construto humano para regular o viver, onde há a constante da mudança, contínua, necessária - não se bebe duas vezes a água do mesmo rio -; num fluir que impõe uma actualização sustentada, exigindo auto-eco-compatibilização do viventeactor: respondendo à envolvente e também em interacção com os outros, porque em sociedade-comunidade.

$\mathrm{Na}$ contínua emergência que nos implica, actualmente com a problemática da comunicação à distância, com explosão da tele/web-tecnologia instrumental, reveremos conceitos-acção de energia, tempo, empatia, auto-ecocompatibilização linguagem-expressão-comunicação, entropia, distopia e utopia e - sendo que vemos esta como a orientação da energia transformadora para o imaginável, não impossível pois até existe conceptualmente, mas só atingível na medida de um possível que para ele vá tendendo.

\section{Compreenderemos 3 enfoques:}

1. Motor/factores do evolver da educação estética visual (EEV) para todos os adolescentes em Portugal - tempo diacrónico - em paralelo com EEV em tempo sincrónico presente. Documentação de tendências referenciais.

2. Tempo legislado para o ensino-aprendizagem específico e tempo necessário para a docência e investigação-acção do professor, específica e em suas interacções.

3 Tempo histórico do âmbito disciplinar da EEV. Potencial de um Exploratório contínuo, dos projectos escolares pioneiros:

- Património cultural imaterial - de memória e referencial de acção, para o não retrocesso da qualidade, em ecocompatibilização contínua -. Extensões espácio-temporais da EEV, nacional e internacionalmente.

Prosseguimos uma metodologia de questionamento a profissionais no terreno, que tencionamos vir a completar com pareceres da comunidade não de EEV; e estudo de casos de projectos no terreno (ExplorEAUL) - a escolas donde tivemos notícia de pioneirismo ou constrangimentos - até Fev. '20 directamente e depois por mail: são indicadores/ referenciais da qualidade a que no país se tem chegado em EEV mas, dada a reduzida amostra, de representatividade não generalizável.

\section{Reflexão de chão e horizonte}

Revemos conceitos-acção, por definições operacionais, de energia, tempo, empatia, linguagem-expressãocomunicação, tele/web-tecnologia instrumental, entropia, distopia e utopia.

. Energia é a capacidade de algo de realizar trabalho, ou seja, gerar força num determinado corpo, substância ou sistema físico. Etimologicamente, este termo deriva do grego "ergos", cujo significado original é literalmente "trabalho".
Na Física, a energia está associada à capacidade de qualquer corpo de produzir trabalho, ação ou movimento. O conceito de energia é utilizado no sentido figurado para designar o vigor, a firmeza e a força. (significados.com.br/ciência).

. Tempo. Em 3 acepções, desde a Grécia antiga: khrónos - cronológico, ou sequencial, medível, associado ao movimento linear das coisas terrenas, contínuo, com um princípio e um fim; Kairós - momento indeterminado no tempo, em que algo especial acontece, o tempo da oportunidade; e Aiõn- sagrado e eterno, sem uma medida precisa, um tempo da criatividade, não cronológico; do movimento circular dos astros; destino, idade, geração, era, eternidade. Wikipedia (em 05.07.2020). Abordá-lo-emos em diacronia - principais conquistas no evolver da EEV -, vs. sincronia - algumas tendências emergentes verificadas no presente.

Empatia - Consideramo-la o fluxo de eu-tu (M. Buber, 1971), relação entre Professor-Aluno(s) em que se procura a compreensão da posição do Outro, em canal-alicerce de toda a intervenção educativa, viabilizando a motivação.

- Auto-eco-compatibilização - processo de actualização sustentada em resposta à eco-emergência, a mudança contínua na casa comum, da evolvente local-global; e em construção-partilha com os outros.

. Linguagem-expressão-comunicação - Será a formalização da dinâmica formativa, de crescimento e expansão no binómio professor-aluno(s), aberta à emergência envolvente: em EEV, através dos meios das Artes Visuais e Multimédia, em conexão com os outros âmbitos do saber: a partir do(s) aluno(s).

. Tele/web-tecnologia instrumental - Recurso da técnica presente, com potencial para ser meio formativo, estratégico num constrangimento de distanciamento. Não esqueçamos, todavia, que, sócio-culturalmente, como Mc Lhuan alertou, o meio é a massagem: pode transformar-se em fim, na mensagem. Mc Luhan, N. (1996).

. Entropia - (1. Física) Medida da desordem de um sistema, ou: da quantidade de energia não convertida em trabalho mecânico. 2. Desordem ou imprevisibilidade. (https:// dicionario.priberam.org/entropias) [consultado em 10-052020].

. Neguentropia - Entropia negativa - 1. [Física] Medida da ordem de um sistema. 2. Ordem ou previsibilidade.

(https://dicionario.priberam.org/neguentropia) [consultado em 10-05-2020].

- Utopia - Entendemo-la como a orientação da energia transformadora para o imaginável, não impossível pois até existe conceptualmente, mas só atingível na medida de um possível que para ele vá tendendo. - Construto in: Oliveira, E. (2010). 
- Distopia - Ideia ou descrição de um país ou de uma sociedade imaginários em que tudo está organizado de uma forma opressiva, assustadora ou totalitária, por oposição à utopia. https://dicionario.priberam.org/distopia) [em 1005-2020]. Este conceito tem sido destacado recentemente e o MAAT-Lx já Ihe dedicou exposição.

O viver implica a emergência contínua. / Esta, exige-nos auto-eco-compatibilização sustentada. / O caminho terá de ser eco-descoberto e aprendido em percurso - com a envolvente e com os outros. / A orientação para progresso, sem modelos úteis face à velocidade e natureza imprevisível da mudança, precisará de referenciais - conquistas no tempo:

\section{- A prosseguir? Com que novas soluções?}

1. Motor/factores do evolver da educação estética visual (EEV) para todos os adolescentes em Portugal - tempo diacrónico.

Incidimos na adolescência por ser uma fase de desenvolvimento que urge cuidar, estudar, apoiar, uma vez que nela se situa a meta da escolaridade obrigatória (agora $\mathrm{n}$ no 12 o ano), onde verificámos, pela nossa investigação (Oliveira, E. 2004/5 e 2010), que se atinge a autonomia da capacidade de critérios de crítica; e porque consciencializamos a responsabilidade da Universidade, em interacção com as Escolas, na formação de Professores, com enfoque nas idades 12-18.

No Ensino Secundário encontramos Cultura e Artes Visuais, mas não em tronco-comum para todos.

O que, até ao final do 9o ano da escolaridade, for trabalhado pelos alunos, será a base para a sua autónoma educaçãoao-longo-da-vida

Neste contexto, poderemos assinalar marcos na EEV para todos em Portugal, alguns impulsionados por Reformas curriculares, que classificámos diacronicamente em 8 períodos, de 1936 ao presente. Oliveira, E. (2004/5, 2010).

P1.1936 - 1947/8- Pró-maginação: Grandes Exposições de Trabalhos visuais de crianças e cultura artística interdisciplinar na Escola (M. M. Calvet de Magalhães); oficialização do Desenho Livre (1947/8, A. Betâmio de Almeida -ABA).

P2. 1947/48 - 1970 - Educação através da Arte: Imaginação, a partir de exercícios de Composição Decorativa. Colagem. Tridimensão. Exposição escolar.

P3. 1970-1974 - Formal: Exercícios bauhausianos com meios visuais (feltrógrafo...)Composição. Desenho de observação extensional (ABA). Apreciação semiológica e de crítica visual, com recurso a retroprojector, diaprojector e cinema.

P4. 1974-1975 - Cultural-Comunicativo: Abertura à cultura e visual - património material visual; cartaz, cartoon, BD, fotografia, (audição e capas de) vinil, vídeo.
P5. 1975-1990. Integrado-Envolvimentalista: Introdução do Design (Programa: ABA, D. Sobral e E. Oliveira). Trabalho de projecto, com aplicação à envolvente; património cultural. Integração da instalação e da performance/teatro. Computador.

P6. 1990-2001/04. Funcional-Tecnológico: tentativa de integração das Artes com as Tecnologias. Oficina de Artes. Projecto de trabalho.

P7. 2001/2004 - 2019. Interaccional-Eco-Tecnológico. Acentuação ecológica de materiais reciclados. Parcerias com Museus. Mais recentemente, Projectos de Agrupamento de Escolas (3-18 anos), integrando alunos com necessidades especiais e interagindo com a comunidade,

P8. 2019 - (Transição). Autonomia e Fexibilização em EEV: Autarquias chamadas á responsabilização educativa. E desde a pandemia covid19, Março '20, acentuação do binónio ensino presencial - ensino à distância, incluindo o recurso a computador (Zoom...), tablet e telemóvel.

Repensar o currículo em EEV (actividades/conteúdos) actualizando a pertinência e relevância da sua resposta específica às exigências emergentes, é uma prioridade para a salvaguarda da formação dos alunos e para a continuidade deste âmbito do conhecimento-acção e seu professorado. Até onde chegámos?

Sincronicamente, verificamos nos Projectos escolares da EEV presente - muitas vezes $c$ / implicações interdisciplinares e em Escolas e Centros Arte-Educacionais não formais, se em parceria com estas, não substitutivamente - as

seguintes tendências referenciais:

11 Modalidades (M) de Ver e Fazer/Dar-a-ver, em crescente interacção

M 1 - Tecnologias

M 2 - Quotidiano/Acaso/Ciência

M 3 - Design

M 4 - Instalação

M 5 - Património cultural artístico/História de Arte

M 6 - Eco-intervenção

M 7 - Carácter/Desenvolvimento pessoal

M 8 - Performance

M 9 - Interacção - Cinema/Teatro

M 10 - Interacção - Escrita/Poesia

M 11 - Interacção local-global

(M12 - Trabalhos com Objectivos Mínimos). É uma tipologia de regresso aos exercícios, que alguns professores têm (transitoriamente?) incrementado, para integração 
de alunos com dificuldades de linguagem verbal (muitas nacionalidades) e técnica. A Embaixadora das Artes Visuais, Nádia Torres observou em escolas do Distrito de Beja, casos de uma outra regressão: os desenhos prontos, para colorir, sem qualquer criatividade!

Alguns Projectos escolares relevantes no País, em EEV e interdisciplinares - Exemplos de Conquistas-Tendências, paralelos no tempo

\section{Tendência 7. Desenho de Expressão não condicionada}

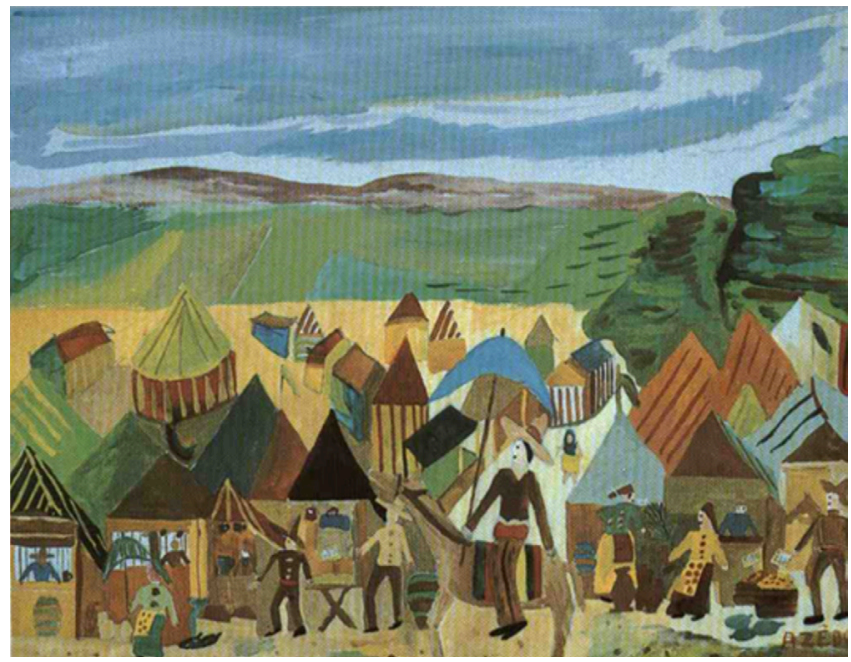

Fig. 1. Desenho Livre. Azêdo - 15 anos. Prof. A. Betâmio Almeida. L. N. P. Nunes, Lisboa. '67.

De: Arquivo Betâmio. In: Ficha 3 do ExplorEAUL (Oliveira. E. 2010).

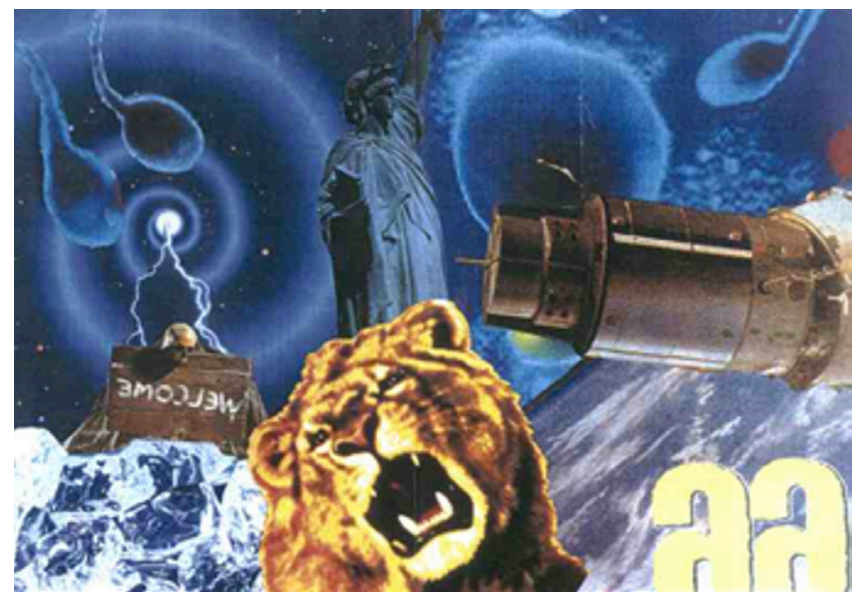

Fig. 2. Colagem individual-Projecto Imagem e Imaginação, orientado por Diogo Félix, E. S. Seomara da Costa Primo, Amadora. '97. In: Ficha 133 - ExplorEAUL (Oliveira. E. 2010).
Tendências 1 e 2. Tecnologias e Quotidiano. Observação

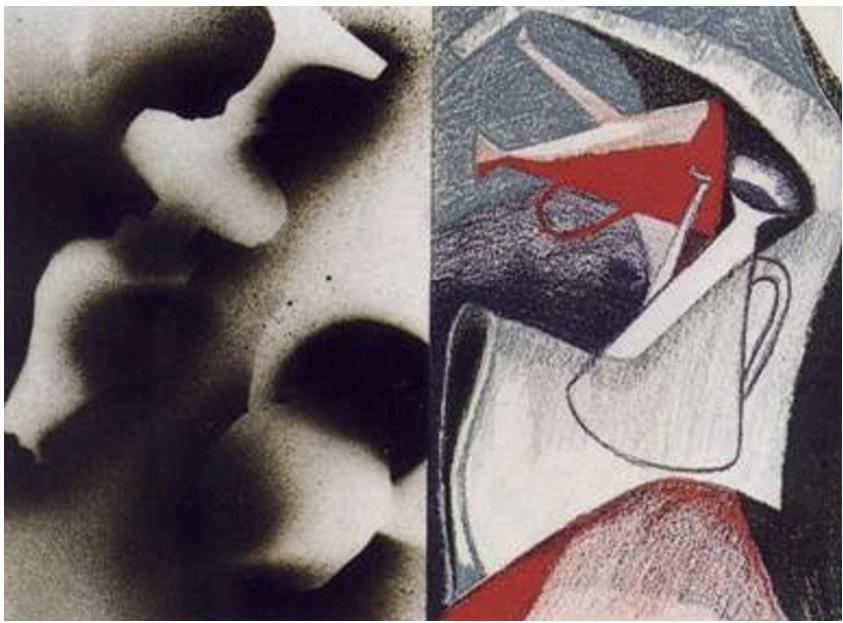

Fig. 3. Desenho Analítico Extensional. Alunas de Elisabete Oliveira. Liceu de Queluz. '72 e '73. Foto: António Góis. In: Educação Arte Cultura, ed. FCG, 1996. ExplorEAUL 40.

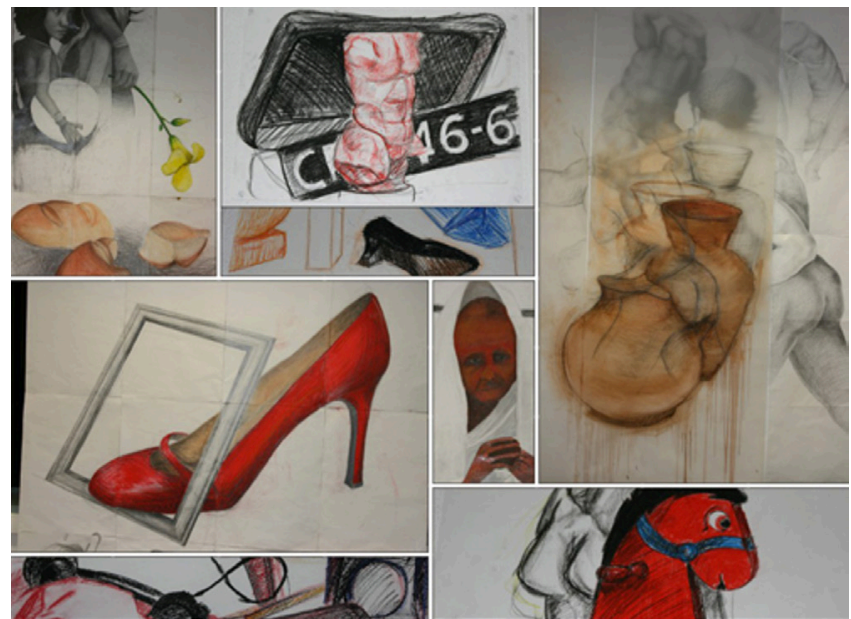

Fig. 4. Fotomontagem, C. O. Fotográgico.Aluno c. 16 anos. Prof. Samuel Pinheiro. E. S. Seomara da Costa Primo, '16.

Tendências 5 e 6. Património Artístico e Eco-Intervenção

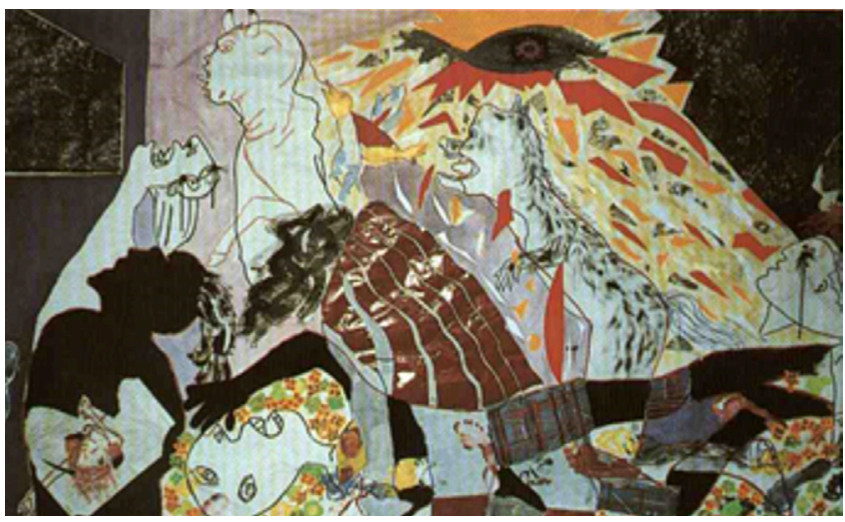

Figs. 5. Eu e os outros, Guernica - Colectivo 6응-12 anos. Prof. Ana Teixeira, c. $230 \mathrm{~cm}$ larg. E. C+S D. Carlos I-Sintra. '94. Exposto np Congo Europeu InSEA, Lisboa '94. ExplorEAUL 117. 


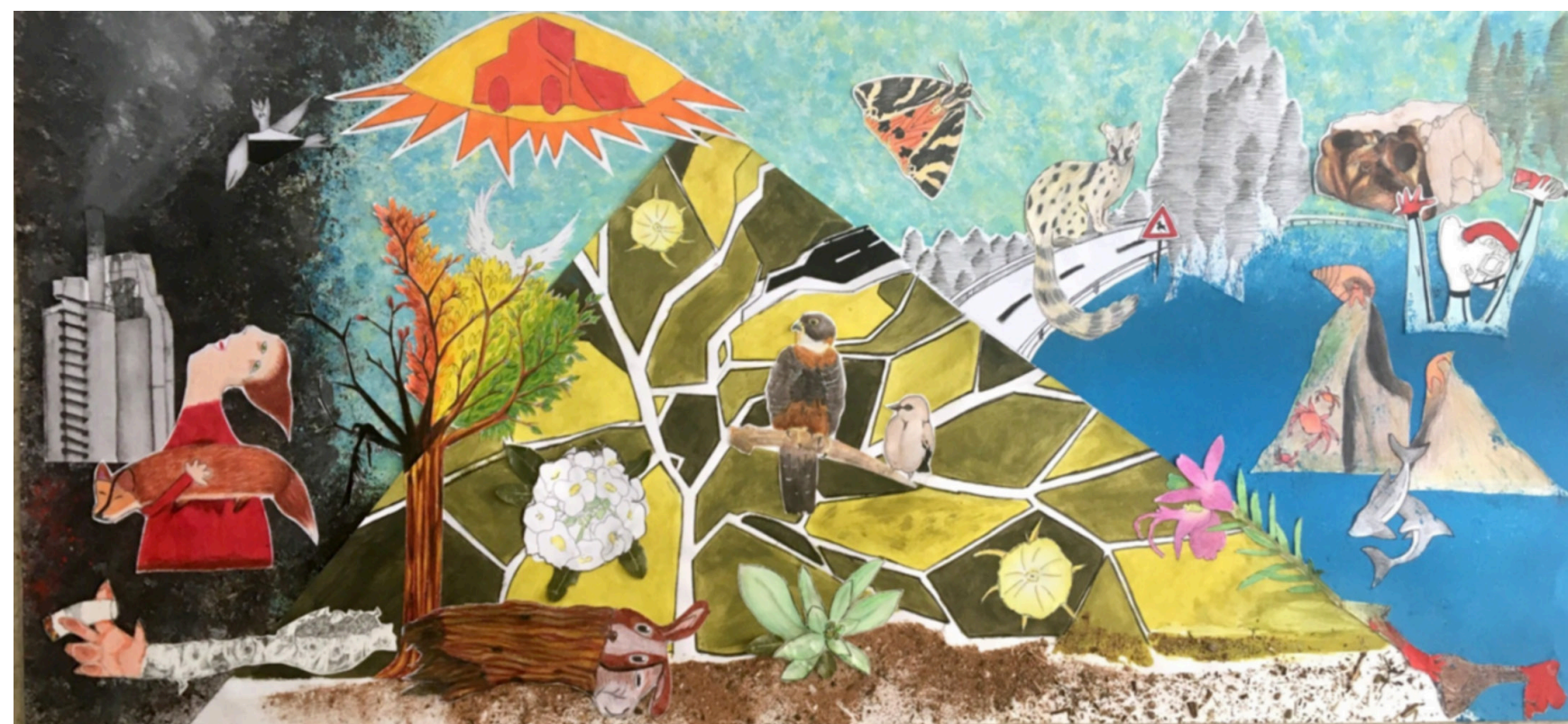

Fig. 6. Arrabida Storming/Biosfera. (Refa Guernica retomada), '18. Prof. Alexandra Seabra (filha de Ana Teixeira). E. Sec. da Moita, 10 ano-B. $78 \times 35 \mathrm{~cm}$. 1으 Prémio KID'S GUERNICA - AMRS, Ensino Secundário. In: Comunico. E. Oliveira,, Actas Congro. Matéria Prima '19 - CIEBA/FBAUL.

Tendências 4, 7, 8, 11 Instalação. Carácter/ Desenvolvimento pessoal.

\section{Interacção local-global. Necessidades Especiais}
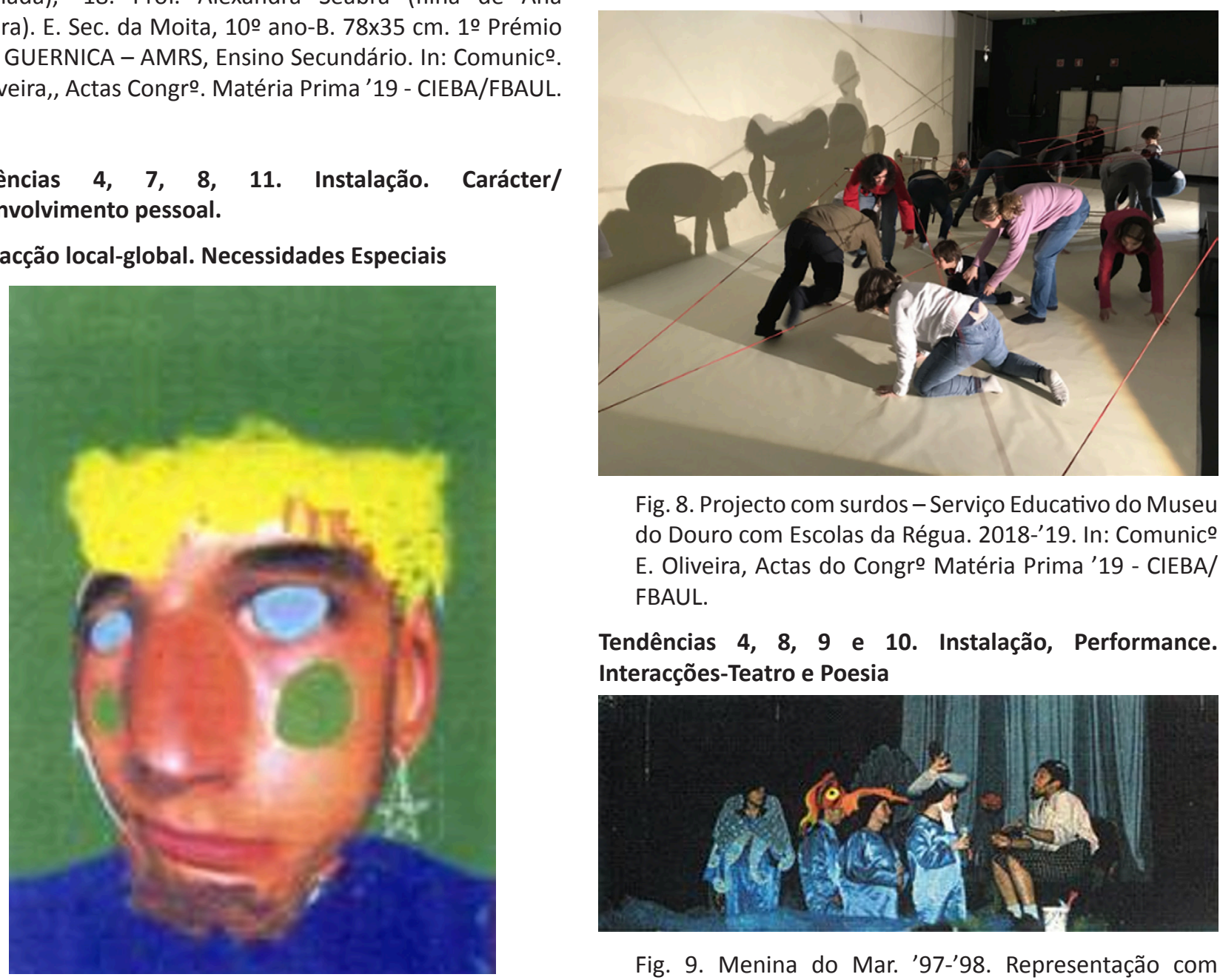

Fig. 8. Projecto com surdos - Serviço Educativo do Museu do Douro com Escolas da Régua. 2018-'19. In: Comunico E. Oliveira, Actas do Congro Matéria Prima '19 - CIEBA/ FBAUL.

Tendências 4, 8, 9 e 10. Instalação, Performance. Interacções-Teatro e Poesia

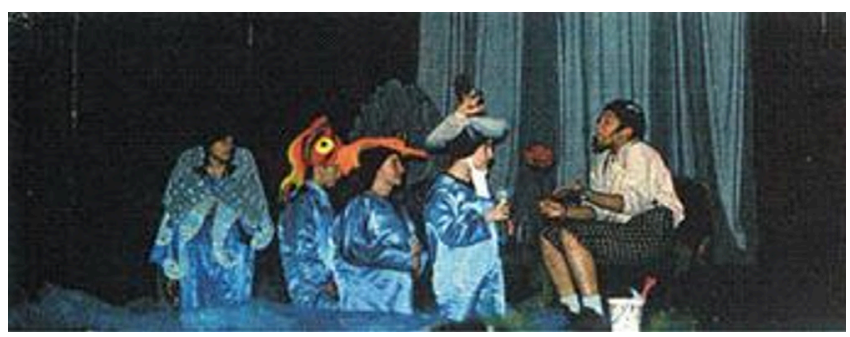

Fig. 9. Menina do Mar. '97-'98. Representação com

Fig. 7. Retrato. Aluno de 16 anos. 70 Ao. '99. Prof. Inês Silva Instituto José Rodrigues Pereira (Surdos). Casa Pia. ExplorEAUL 136. guarda-roupa pelos Aluno 8 D - 13/14 anos. EB 2.3 Pedro de Santarém, Lisboa. Prof. Albertina Sousa. ExplorEAUL 158 e Oliveira, E. (2008). 


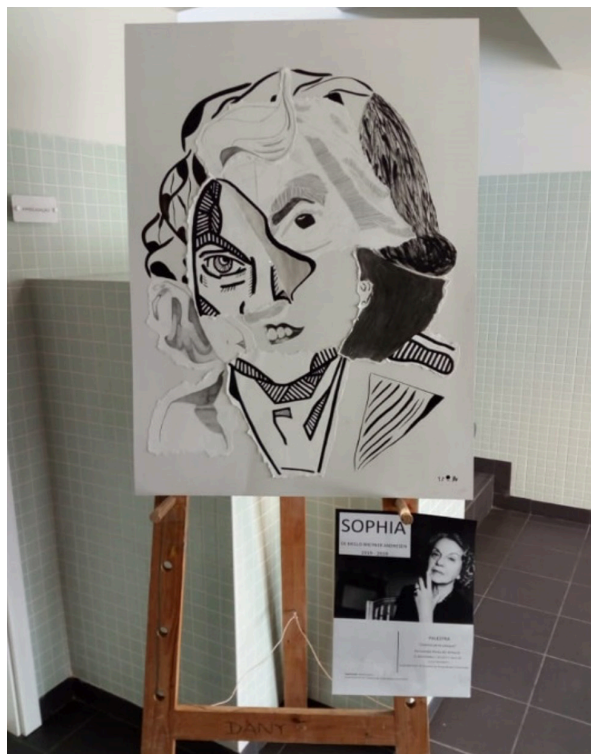

Fig. 10. Menina do Mar. '20. Instalação (pormenor) para Conferência s/ Sophia M. Breyner. Foto recebida da Prof. Eugénia Melim*. E. Sec. Dr. F. Freitas Branco, Porto Santo.

*Estando esta Escola desde '18 em obras demolidoras, agravadas pelo contexto pandémico, num mail de 7 Abril'20, Eugénia Melim anota: A sala de trabalhos para o secundário é uma arrecadação com 2 cadeiras, sem luz natural, sem água e com apenas os cinco estiradores necessários aos alunos. Projectos em suspenso...

\section{Tendência 3. Design}

Exo. aqui não documentado mas apresentado em Congresso Matéria Prima - CIEBA/FBAUL: Em aula do Prof. José Miguel Gervásio, c. '16, E. Sec. de Montemor-o-Novo, os alunos fizeram o re-design das carteiras novas, deficientemente projectadas pela remodelação P. Escolar.

Tendências 1 e 11. Tecnologia informática e Intervenção na Comunidade

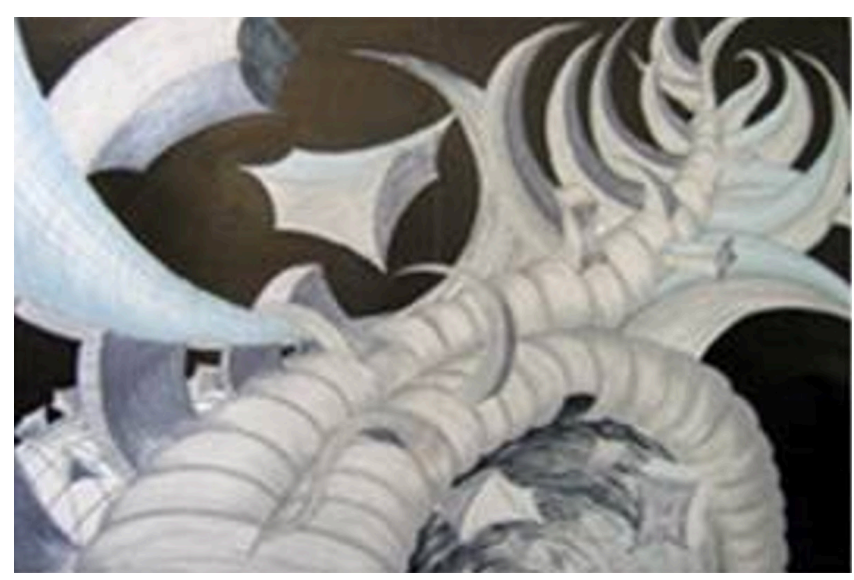

Fig. 11. A Floresta Artificial. (Multimedia). '09. Ruben Lourenço. 11으으-17 anos. Prof. Paulo Benjamim. E. Sec. António Arroio, Lisboa. ExplorEAUL 171; Oliveira, E. (2010).

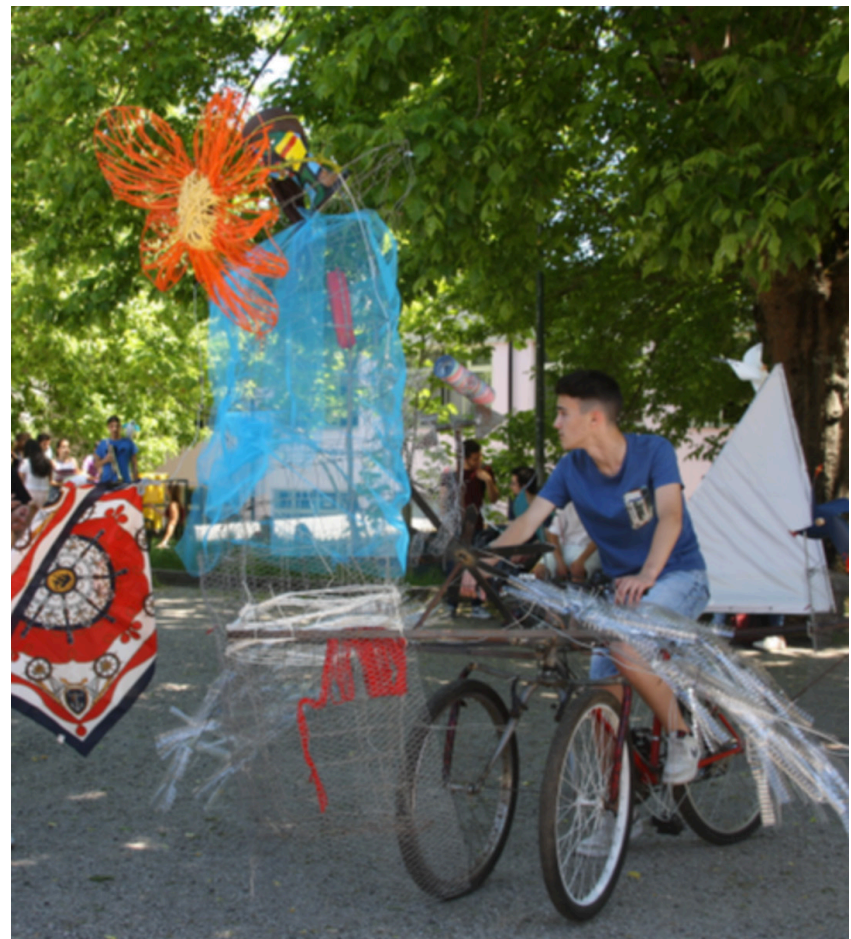

Fig. 12. Nau Catrineta (Fo de Magalhães), '19. Colectivo em Projecto Agrupamento, 11으으. Prof. Cristina Pinto. E. Sec. Valbom: cortejo c/ as peças, performance e expo. L. do Desenho-Resende.

Refletimos sobre uma aprendizagem de linguagem, operacionalidade tecnológica e crítica específica de artedesign que, abrindo as escolas portuguesas ao trabalho de projecto e ao projecto de trabalho, tornaram este âmbito de vasta instrumentalidade em trans-disciplinaridade cívica, ambiental. Questionamo-nos:

Ameaça de diluição/extinção da EEV-corpo de saber-fazerser específico?

Temos apresentado, com sucessivos ajustamentos, uma proposta de Currículo de EEV estruturante, indispensável ao perfil de saída no 3o Ciclo. In: Oliveira, E. (2004/5; 2010) e Congressos Matéria Prima - CIEBA-FBAUL.

Cada Professor e cada Escola, cada Autarquia, têm agora legislação de flexibilização e responsabilidade autónoma para auto-eco-compatibilizarem esse currículo com a emergência.

2. Tempo legislado para o ensino-aprendizagem específico e tempo necessário para a docência e investigação-acção do professor, específica e em suas interacções.

É necessário o tempo para o professor se informar e refectir; planear projecto de trabalho a partir de e inter-alunos em presença; facilitar a realização; avaliar cada experiência formativamente (contínua e sumativamente) também COM os alunos e auto-avaliar a sua própria performance; disseminar/compatibilizar resultado dos alunos e das suas 
próprias metodologias, nos contextos sócio-culturais e científicos, nacionais e internacionais, envolvidos ou em interacção possível...

Urgemelhorarem-seas condições desta dinâmica profissional profunda e necessária; e acordar a consciencialização da Tutela, através dos meios associativos - da sua prioridade vs. burocracias dispensáveis e time-consuming.

\section{Legislação a ponderar.}

. Lei de Bases do Sistema Educativo, Lei № 46/86 de 14 Outo.; redacção actual - Autonomia e Flexibilização Curricular: DR - Série I. № 129 - 6.7. '18. Nossa Nota ao Art.o 23: Refere. se aqui: Avaliação formativa e sumativa. Desde Oliveira, E. (2004/5), defendemos que toda a avaliação é formativa, podendo ser contínua ou sumativa.

. Intervenção Educacional das Autarquias: Lei 21/2019, DR. Série I. de 30.011.2019.

3. Tempo histórico do âmbito disciplinar da EEV. Potencial de um Exploratório contínuo,

Fig, 13. Ficha 201 do ExplorEAUL, formatada, preenchida por Alexandra Seabra para o seu Projecto Arrabida Storming Guernica (Fig. 6).

F2-F9 dos projectos escolares pioneiros. Extensões espáciotemporais da EEV, nacional e internacionalmente.

Urge que o Professor inclua na sua rotina de planificação de Unidades Didácticas, o respectivo registo-relatório, como por exemplo é proposto na Ficha do ExplorEAUL, cujo formato (máximo: A4), se apresenta em seguida.

Assim se consolidará um repositório da EEV dos Adolescentes em Portugal, aberto, - Património cultural imaterial, de memória viva e referencial de acção, para o não retrocesso da qualidade, em eco-compatibilização contínua.

Ficha 201 do ExplorEAUL, Projecto Arrabida Storming.

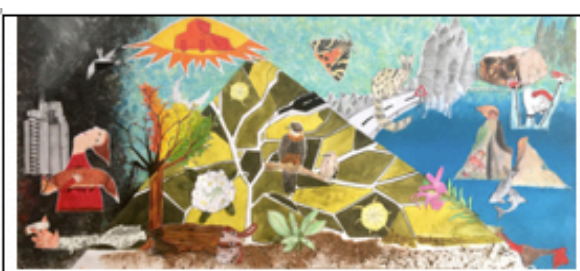

Título: "Arrábida Storming" - Recriação do Gueraica Participação no Projeto Kid's Guernica 2017/18 Tema: Arrábida Biosfera. Subtemas: património natural e cultural da Arrábida e sustentabilidade

Orientação: Alexandra Seabra

Autoria: Colectixa de Alunos de Desenho - 10- D1 Data: Janeiro - Maio 2018

Idades: 15-18

Ano escolar: $10^{\circ}$

Escola/Local: E. Secundária da Moita

Técnica: Desenho, Pintura, Impressōes

Dimensāo $(\mathrm{cm}): 0,35 \mathrm{~m} \times 0,78 \mathrm{~m}$

Processo:

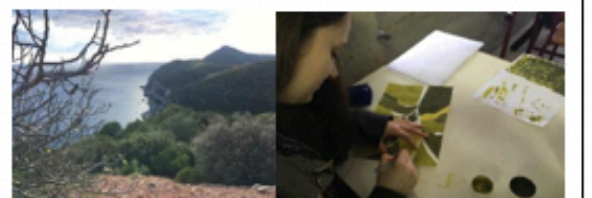

Levantamento de problemas relacionados com a relaçāo homem /natureza (serra da Arrábida)

- Sessão com a artista plástica Ana Teixeira - contexto da realização da obra e estrutura plástica - Visita guiada à Serra da Arrábida - observação direta e representação visual e fotográfica

- Imaginação de um lado "negro" da Arrábida (poluição das fábricas, fogo... utilização indevida): $2 / 3$ do quadro; e outro, com toda a sua beleza - flores, animais, cores, água, biodiversidade - a biosfera.

- Manutenção da estrutura triangular do quadro Guernica, assemelhando-a à forma da Serra. Representação de arbusto (simplificação por nivelamento), retratando a paleta de cores da Serra.

- Representação de elementos do Guernica em novo contexto, desenhando-os a partir dos elementos trazidos da Arrábida, das fotografias efetuadas, de pesquisas online e bibliográficas (em livros da Biblioteca). $\mathrm{O}$ trabalho foi pensado e repensado até à configuraçāo do painel final.

Disseminação:

Exposição itinerante pelas escolas do Concelho da Moita. Divulgação no Site da Associação Municípios da Regiāo de Setúbal:

https://www.amrs.pt/pages $/ 378$ ?news id $=668$

Contributo para Comunicaçōes de Elisabete Oliveira aos Congressos Internacionais Matéria Prima '19 (CIEBAFBAUL) e APECV 32 online, ' 20.
Ficha 201. Educação Visual Anos '40 - Contínuo Investigaçăo. Elisabete Oliveira 2010-2020 Fotos: Alexandra Seabra 
O intercâmbio comparativo de um tal ExplorEAUL, servirá à valorização qualitativa respondente à sociedade em crescente tecnologização (até pós-humana) e globalização, mas com grandes contrastes de acesso e expansão (interior vs. litoral; grande cidade vs. periferias aqui; países desenvolvidos vs. 30 mundo...

\section{A ACENTUAÇÃO DA URGÊNCIA DE PONDERAR O QUE É} RELEVANTE EM EEV no contexto da emergência presente e futura.

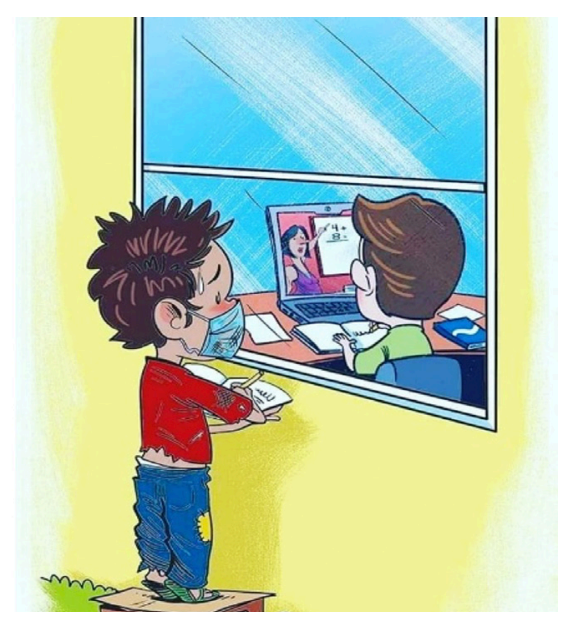

Fig. 14 . Art.o 53 - Direito à educação da criança e do Adolescente. ECA (Estatuto da criança e do adolescente). Doc. da internet, incluindo Cartoon, que agradecemos ao Prof. Alexandre Falcão.

(Artigo54). \#direito \#eca \#direitoaeducaçao \#direitodacriançaeadolescente \#direitoconstitucional \#direitocidadao \#Justiçacidadã \#justiça ».

\section{QUESTIONAMENTO:}

O que será preciso fazer acontecer toda a população escolar ter os meios necessários de acesso à educação estética visual., em algum grau à distância se forçoso, mas esta sempre complementada com co-concretização e intervenção?

Inquirimos Professores de EEV - discussão em rede -, sobre a possibilidade de, na versão de ensino à distância de Educação Visual se poder salvaguardar uma metodologia de projecto eco-aplicável e em equipa?

As respostas podem estimular outros para a reflexão e busca de soluções:

- Nádia Torres, Embaixadora de Educação Visual desde Mértola, 24.04.'20:

EV a distância e em rede, claro que é possível. O problema reside no domínio da tecnologia da parte dos professores. Deveria existir uma formação nesta área para prof de EV.
- Cristina Pinto, E. Seca de Valbom, 24.04.'20:

Pensando no assunto, não me parece impossível. $O$ projecto teria que ser pensado primeiro o todo $e$ depois as partes. Usando materiais descartáveis que todos têm em casa, dando as diretivas certas a cada um explicando-Ihes o objectivo, no fim as partes serão reunidas e montadas. $E$ isso parece-me possível tanto em bidimensional como em tridimensional.

Pensando mais no assunto, o trabalho poderia ser uma acção de sensibilização, com produção de algum material e uma performance combinada, devidamente registada em pequenos filmes que depois se aglutinariam.

\section{- Alexandra Seabra, E. Sec. da Moita. 26.04.'2:}

(...) eu estou precisamente ainda a elaborar a minha planificação para o trabalho de ev do go ano e após algumas formações realizadas estes dias, ando às voltas com o assunto. Nem tinha pensado na viabilidade de fazer um projeto coletivo, mas parece-me possível. Tenho pensado que seria mesmo importante recorrer às tecnologias uma vez que é agora mais do que nunca que os alunos aí estão. para apresentar o projeto aos alunos realizar uma webquest (penso que conhecerão) é uma boa estratégia; depois de todos terem concluído a sua parte, poder-se-ia reunir tudo num conjunto. Estou a pensar por exemplo na recriação de uma obra, poder-seia reconstruir uma coletiva agregando pedaços de todos. o que acham? Agradeço (...) a possibilidade de estar a participar nesta discussão.

- Samuel Pinheiro, E. Sec. Seomara da Costa Primo, Amadora. 20.04.'20:

A metodologia de PROJETO até pode ser potenciada à distância utilizando os meios digitais. É o que está a acontecer com o projeto de vídeo na disciplina de Oficina Multimédia em que desde o argumento até ao storyboard, realização e produção está a ser conseguido em grupo. A partilha foi potenciada porque estando em confinamento foi necessário dialogar entre todos sobre os programas free disponíveis e quais seriam os mais recomendados. Penso que vai correr bem contextualizando as limitações e restrições.

Desenvolvemos um PROJETO COM PESSOAS no CUrSO Profissional de Fotografia que foi o de fotografar um determinado espaço interior ou exterior sem pessoas $e$ posteriormente o mesmo passo com pessoas, estudando o enquadramento e a iluminação; para depois proceder à avaliação das diferenças das duas fotografias. Percebeuse que a fotografia com pessoas sugere melhor uma história e traz outra dinâmica e sensibilidade na leitura do espaço. Um outro projeto que foi lançado foi o de 20 OLHARES diferentes sobre a escola. O trabalho de um 
dos alunos foi muito inovador. Durante o confinamento estamos a lançar o projeto A MINHA JANELA.

Vd. Samuel Pinheiro, Sites seleccionados. Apêndice a Referências Bibliográficas

Esta recolha pateteia o contributo em Investigação-Acção e Práticas relevantes, dos Professores nas Escolas, em rede com a Investigação Universitária em Didáctica da EEV: incluímo-la na íntegra, pela energia rizomática* informativa e pró-activa que irradia. (*Deleuze. G. 1969),

\section{Reflexão conclusiva}

Constatando a conquista de valor formativo do ensinoaprendizagem pelo processo de projecto de trabalho em EV e Artes Visuais em Escolas do país, impõe-se que neste se progrida em: (1) Vigilância dos constrangimentos redutores emergentes de distanciamento; dificuldades de acesso e domínio tecnológico, tempo e espaço: impedindo-os de causarem retrocesso da qualificação. (2) Garantia do acesso, em todo o País, a uma formação de professores de EE e Artes Visuais (de 3 Ciclo e E.o Secundário, no nosso enfoque), consciente da realidade que tentámos analisar; e com urgência, pois a actual legislação de autonomia e flexibilização curricular

Esta mudança no tempo coloca-nos o questionamento: - Qual o equilíbrio das experiências de apreciação vs. concretização de projectos dos alunos? Consideramos que o valor formativo destes projectos deve continuar a ser fundamental: um ponto de água no fundo da sala, apontará à salvaguarda de manualidade e será precisa a auto-eco-compatibilização contínua com as tecnologias emergentes. Refletindo sobre a aprendizagem de linguagem, operacionalidade e crítica específica de arte-design, com tempo lectivo cada vez mais reduzido, e a instrumentalidade deste âmbito, em trans-disciplinaridade, ameaça de diluição/extinção? descentraliza a responsabilidade decisória, de acção e accountability para as Escolas/Professores, em diálogo com as Autarquias; e constatámos, por exemplo, que já não há formação para professor de EEV nos Açores, forçando ao recurso à Madeira ou ao Continente. (3) Maximização de sinergias, pela partilha de referenciais e práticas estruturantes em plataformas e redes. O ExploEAUL (de cujas Fichas incluímos 9 Projectos neste Artigo, e 4 em preparação), pode servir como recurso relevante: património cultural imaterial, memória e referencial de investigação-acção, para o incremento da qualidade, em auto-eco-compatibilização contínua.

\section{Referências}

Bhabha, H. (2007). A Urgência da Teoria. Lisboa: FCH, pp 42-3.

Betâmio, A. (1967). Ensaios para uma Didáctica do Desenho. Lisboa: Escolar Editora.

(1968). Uma Visão Táctil: Eduardo Viana. In: Diário de Lisboa, anos '60-'70.

Betâmio, A. Betâmio, A. (1968a). A Educação Estética. In: Palestra № 31. Janeiro.

Betâmio, A. \& AA. (1968b). Curso Básico de Arte - Um Novo Desenho dos Liceus. In: Palestra № 31. Jan. (AA-Equipa de ABA: Abelha, M L; Dantas, S; Viola, M E; Oliveira, E; Sobral, P; Dantas, F; e o Colega do L N Pedro Nunes, Ferreira, L.) - Base do Programa de Educação Visual nacional de '70.

Betâmio, A. (1976). A Educação Estético-Visual no Ensino Escolar. Lisboa: Livros Horizonte.

Betâmio, A. \& AA. (1977). Educação Visual. Vols. 1 e 2 (7ํ e 8o Anos de Escolaridade). Lisboa: Didáctica Editora. Compêndio para alunos; não obrigatório.

Buber, M. (1971). Between man and man. London. Fontana Library.

Damásio, A. (2000). O sentimento de si. O corpo, a emoção e a neurobiologia da consciência. Mem-Martins: Publicações Europa-América. 2001.

Damásio, A. (2017). A estranha ordem das coisas. A vida, os sentimentos e as culturas humanas. Lisboa: Temas e Debates. Círculo de Leitores, 365

Deleuze, G. (1969). Logique du Sens. Paris: Éditions de Minuit.

DR-ME: Lei de Bases do Sistema Educativo, Lei № 46/86 de 14 Outo.; redacção actual - Autonomia e Flexibilização Curricular: DR - Série I. № 129 - 6.7. '18. / Intervenção das Autarquias: Lei 21/2019, DR. Série I. de 30.011.2019.

ECA, 2020. (Estatuto da criança e do adolescente) Arto 53 - Direito à educação da criança e do Adolescente. In: justicacidadamt. 25 Abril '20 Crédito de Imagem, Internet.

Eco, U. (1964). L' oeuvre ouverte. Paris: Ed. Du Seuil.

Ehrenzweig, A. (1969). A ordem oculta da Arte. Um estudo sobre a psicologia da Imaginação Artística. R Janeiro: Zahar EditoresGonçalves, R. M. (2002). A visão, o tacto e a memória. (Betâmio, 2004: 10-12).

McLuhan, M. \& Fiore, Q. (1996). The médium is the massage. England: Penguin Book..

Morin, E. (1990). Introdução ao pensamento complexo. Lisboa: I․ Piaget. 1991.

Oliveira, E. (2004/5). Os Programas da Área de Educaçãp Estético-Visual no Desenvolvimento dos Adolescentes ao Longo das Últimas Sete Décadas e o Processo de Avaliação Formativa pelos Professores.UL-FPCE. Tese de Doutoramento mimeografada.

Oliveira, E. (2008). Coord. Práticas Estruturantes em Educação Estética e Tecnologias Visuais. MinervaCoimbra. Co-Autores: Albertina Sousa, António Bila, Luis Garito, Maria José Amado, Rui Moutinho e Samuel Pinheiro. 
Oliveira, E. (2010). Educação estética visual eco-necessária na Adolescência. Coimbra: MinervaCoimbra.ISBN:978-972-798-293-6.

Oliveira, E. (2005-2020...). ExplorEAUL-Piloto em progresso: Projectos escolares pioneiros desde anos '40, em EEV, em Actas de Congressos (InSEA, APECV, CSO-FBAUL, SPEC; Repositório Pompidou Centre. Paris '07; Univ. Florida, EUA, '07; I. A. Sociology, Univ. F. Pessoa-Br. '08...).

Peirce, C. (1958). Collected Papers. Vol. 8. Harvard: Harvard University Press.

\section{Sites}

ENSINO À DISTÂNCIA - plataformas e programas APOIO ÀS ESCOLAS https://apoioescolas.dge.mec.pt/

PERFIL DOS ALUNOS À SAÍDA DA ESCOLARIDADE OBRIGATÓRIA https://dge.mec.pt/sites/default/files/Curriculo/Projeto_ Autonomia_e_Flexibilidade/perfil_dos_alunos.pdf APRENDIZAGENS ESSENCIAIS https://www.dge.mec.pt/aprendizagens-essenciais APRENDIZAGENS ESSENCIAIS - ENSINO BÁSICO

https://www.dge.mec.pt/aprendizagens-essenciais-ensino-basico

PERFIL DOS ALUNOS PARA O SÉCULO XXI

http://www.cnedu.pt/content/noticias/CNE/Parecer_PerfilAlunos.pdf https://naveavela.com.br/qual-e-o-perfil-do-aluno-do-seculo-xxi/

\section{ESTUDO EM CASA - RTP}

https://www.rtp.pt/play/estudoemcasa/

https://estudoemcasa.dge.mec.pt/

https://www.publico.pt/2020/05/06/impar/opiniao/carta-abertaeducadores-professores-1915217?fbclid=IwAR35fkP8xQjJuKic fA_Vnb3HLNrDWrTF2NOdE76wQbA-bWob9yOx2CTVh70

\section{APOIO ÀS ESCOLAS}

https://apoioescolas.dge.mec.pt/

\section{APRENDIZAGENS ESSENCIAIS}

https://www.dge.mec.pt/aprendizagens-essenciais

APRENDIZAGENS ESSENCIAIS - ENSINO BÁSICO

https://www.dge.mec.pt/aprendizagens-essenciais-ensino-basico

\section{PERFIL DOS ALUNOS PARA O SÉCULO XXI}

http://www.cnedu.pt/content/noticias/CNE/Parecer_PerfilAlunos.pdf https://naveavela.com.br/qual-e-o-perfil-do-aluno-do-seculo-xxi/ 